PubMed

Display Settings: Abstract

J Inorg Biochem. 2012 Sep;114:65-74. doi: 10.1016/j.jinorgbio.2012.04.014. Epub 2012 May 2.

\title{
Synthesis of organometallic ruthenium(II) complexes with strong activity against several human cancer cell lines.
}

Morais TS, Silva TJ, Marques F, Robalo MP, Avecilla F, Amorim Madeira PJ, Mendes PJ, Santos I, Garcia

$\underline{\mathrm{MH}}$.

Centro de Ciências Moleculares e Materiais, Faculdade de Ciências da Universidade de Lisboa, Campo Grande, 1749-016 Lisboa, Portugal.

\section{Abstract}

A new family of "RuCp" $(\mathrm{Cp}=\eta(5)-\mathrm{C}(5) \mathrm{H}(5))$ derivatives with bidentate N,O and N,N'-heteroaromatic ligands revealed outstanding cytotoxic properties against several human cell lines namely, A2780, A2780CisR, HT29, MCF7, MDAMB231, and PC3. IC(50) values were much lower than those found for cisplatin. Crystal structure of compound 4 was determined by X-ray diffraction studies. Density functional theory (DFT) calculations performed for compound 1 showed electronic flow from the ruthenium center to the coordinated bidentate ligand, in agreement with the electrochemical studies and the existence of a metal-to-ligand charge-transfer (MLCT) band evidenced by spectroscopic data.

Copyright (C) 2012 Elsevier Inc. All rights reserved.

PMID: 22698866 [PubMed - indexed for MEDLINE]

Publication Types, MeSH Terms, Substances

LinkOut - more resources 